\title{
Cervical vagal schwannoma mimicking tonsillar mass
}

\begin{abstract}
Vagal Nerve schwannoma are rare nerve sheath tumours. Generally benign, schwannomas grow at the rate of $2.5-3 \mathrm{~mm}$ per year. ${ }^{1}$ They are seen in patients in $3^{\text {rd }}$ to $5^{\text {th }}$ decade of life. No sex predilection has been noted. ${ }^{2}$ Presentation if often as painless, slow growing lateral neck mass. The treatment of choice is complete surgical excision with preservation of neural pathway when possible.,
\end{abstract}

Keywords: benign, schwannoma, vagus

\author{
Volume 10 Issue 3 - 2018

\begin{abstract}
Inderdeep Singh, Sharma SA, Manu V, Phogat
D

Department of Otorhinolaryngology, Head \& Neck Surgery,
\end{abstract} \\ Institute of Naval Medicine, India
}
Correspondence: Shruti Anil Sharma, Department of Otorhinolaryngology, Head \& Neck Surgery, Institute of Naval Medicine, INHS Asvini, Colaba, Mumbai-400005, India, Tel +919823712454, Email shruti.sharma0512@gmail.com

Received: April 06, 2017 | Published: May 25, 2018

\section{Introduction}

Schwannomas are nerve sheath tumours. Head and neck schwannomas comprise $25-45 \%$ of all extracranial schwannomas. ${ }^{4}$ Schwannomas commonly arise from glossopharyngeal, accessory and hypoglossal nerves. They are adherent to nerve of origin Vagus nerve schwannomas are general benign growing at the rate of 2.5$3 \mathrm{~mm}$ per year. They commonly present with hoarseness, dyspnoea, dysphagia, cough, tongue weakness and vocal cord paralysis. It is not uncommon for vagal schwannomas to present as lateral neck masses. Vagal Schwannoma displaces the internal carotid medially and internal jugular laterally. ${ }^{5}$

The treatment of choice is complete surgical excision with preservation of neural pathway when possible. ${ }^{3,6}$ Imaging plays a central role in diagnosing vagal nerve neoplasm and Magnetic Resonance imaging (MRI) has become the routine imaging study for these tumours.

\section{Case report}

A23-year-old healthy male presented to our centre with complaints of dysphagia of 6 months duration. Physical examination revealed a well capsulated firm mass around $4 \times 3 \times 5 \mathrm{~cm}$ arising from the (L) lateral pharyngeal wall displacing the (L) tonsil medially and extending upto the uvula in midline and inferiorly into the (L) vallecula. Indirect laryngoscopy showed both vocal cords mobile.

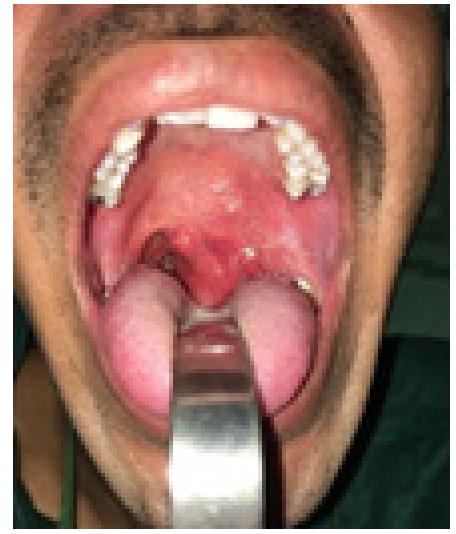

Contrast Enhanced Computed Tomography of the neck revealed an enhancing mass lesion measuring $4.4 \times 3.5 \times 4.5 \mathrm{~cm}$ arising from (L) Tonsillar fossa anteriorly abutting the posterolateral aspect of tongue, posteriorly abutting the prevertebral muscles, loss of definition of anterior and posterior tonsillar pillar and medially bulging in oropharynx. Lateral fat planes with carotid vessels maintained.
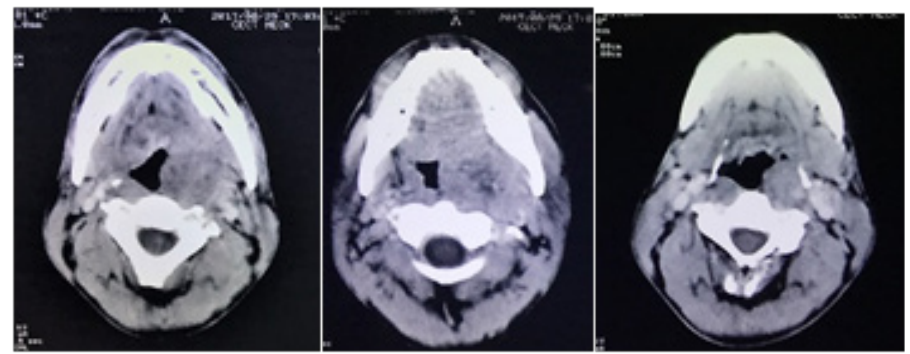

Contrast Enhanced Magnetic Resonance Imaging of Neck demonstrated a well-defined lesion in left parapharyngeal space measuring $6 \times 4.6 \times 3$ with necrotic centre and few vessels giving flow voids and contrast pooling with well-maintained fat planes (Figure 1).
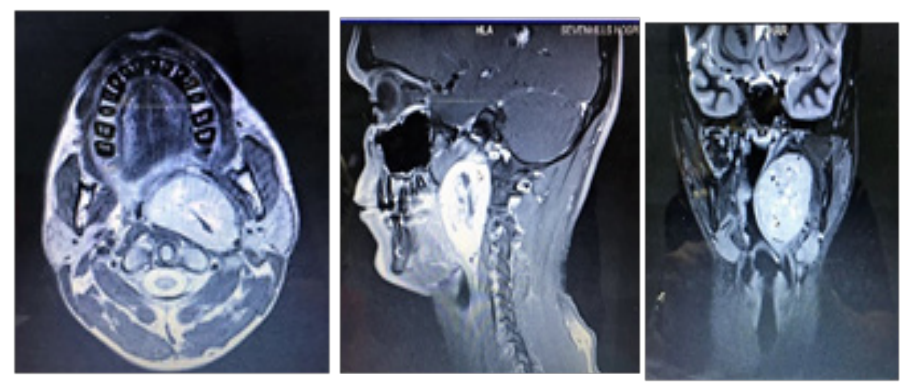

Figure I Biopsy from the intraoral mass was inconclusive.

Cervical approach to the tumour was taken. Carotid sheath was opened and control was taken inferior and superior to the mass. Submandibular gland was excised to achieve adequate exposure of the tumour. A firm yellowish ovoid mass arising from vagus nerve at inferior ganglion nodose was identified. Tumour sheath was opened and dissected from the vagus thus preserving the nerve. Superiorly the tumour was dissected near skull base and below the mandible by blunt dissection, keeping the plane above styloid process. The tumour 
was delivered cervically after pushing digitally through pharynx preserving great vessels and cranial nerves X, XI and XII. Specimen was sent for histopathological examination (Figure 2) (Figure 3) (Figure 4)

Microscopy showed Proliferation of spindle cells with wavy
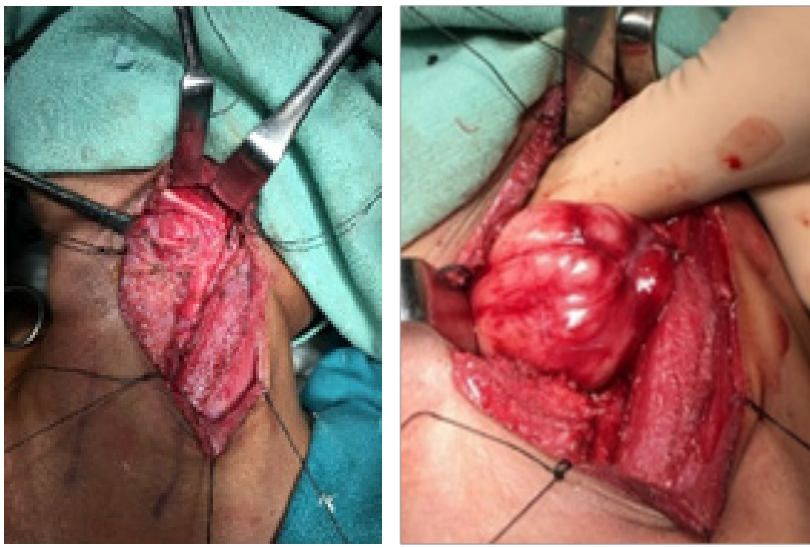

Figure 2 Intraoperative images of the approach and the tumour.

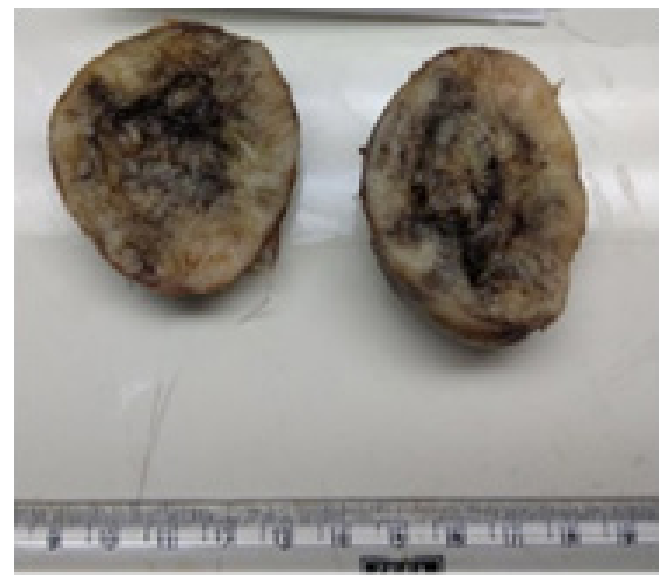

Figure 4 The specimen.

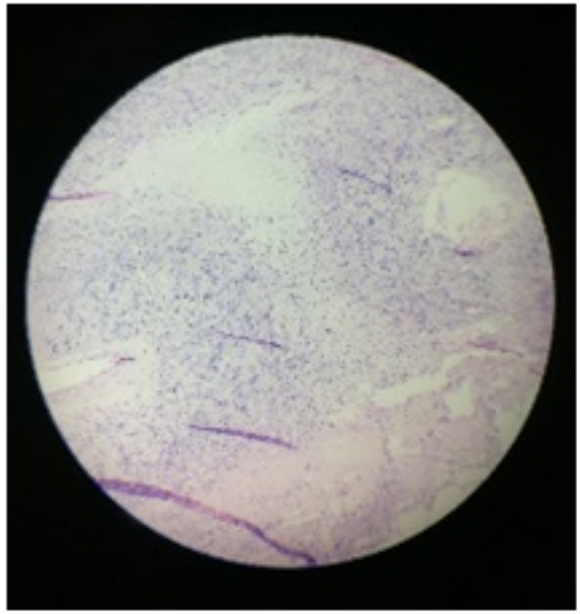

Figure 6 Low power view showing hypocellular and hypercellular areas.

Citation: Singh I, Sharma SA, ManuV, et al. Cervical vagal schwannoma mimicking tonsillar mass.J Otolaryngol ENT Res. 20I8;10(3):I42-I44. DOI: 10.15406/joentr.2018.10.00332 nuclei arranged in intersecting fascicles. Dense areas of spindle cells with eosinophilic cytoplasm with nuclear palisading and nuclear free zones "Verocay bodies" (Figure 5) (Figure 6).

Patient was discharged on $8^{\text {th }}$ post-operative day with Bilateral vocal cord mobility (Figure 7) (Figure 8) (Figure 9).
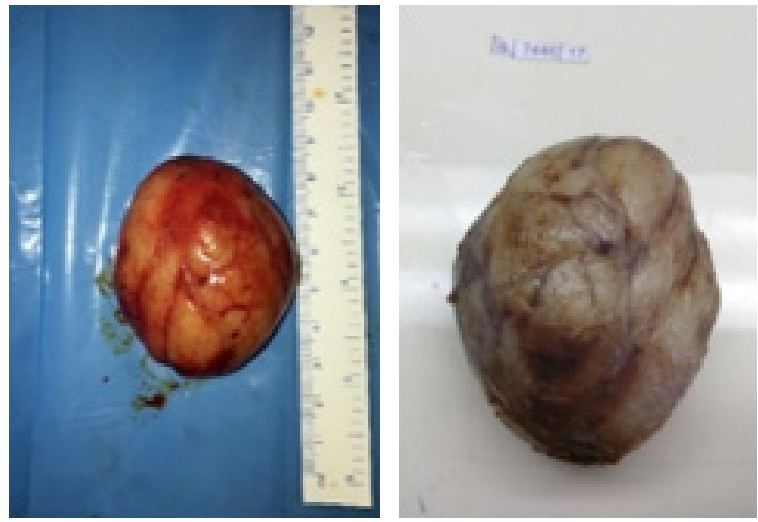

Figure 3 Gross and cut section of specimen.

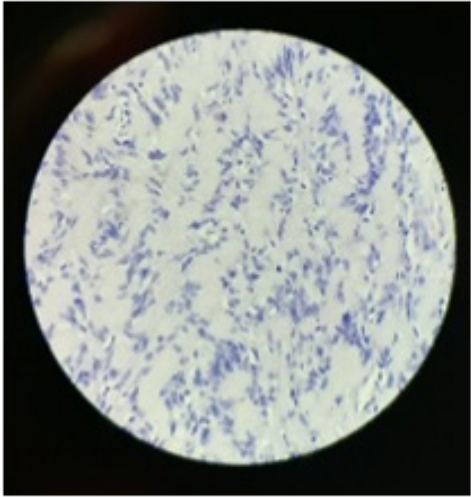

Figure 5 High power view showing Densely cellular Antoni A areas.
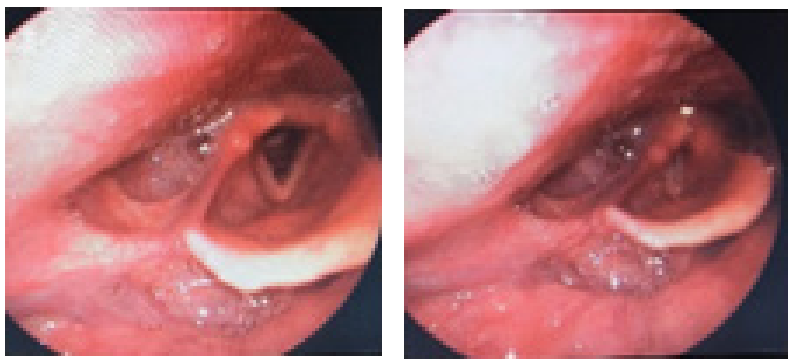

Figure 7 Both vocal cords mobile.

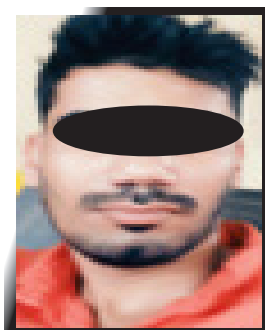

Figure 8 Pre-operative. 


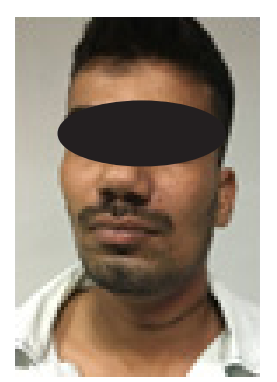

Figure 9 Post-operative.

\section{Discussion}

Vagal nerve schwannomas are a challenge to head and neck surgeons. Multiple treatment options include observation, complete tumour excision with nerve transection and excision with nerve preservation. ${ }^{6}$ Investigations like FNAC have low specificity making pre-operative definitive diagnosis difficult. ${ }^{3}$ Computed tomography and magnetic resonance imaging not only provides insight into the location and origin of the tumour but also aids in surgical planning. ${ }^{7}$ Surgical resection is the standard of care in symptomatic schwannomas. Nerve sparing techniques should be performed wherever feasible to avoid the neurological sequelae associated with nerve transection. ${ }^{8}$ The intimate relation between vagus nerve fibres and tumour capsule requires meticulous dissection for preservation of nerve function. We found that subcapsular dissection of schwannoma from the vagal nerve fibres helped preserve nerve function and achieve an excellent post-operative outcome.

\section{Conclusion}

The purpose is to report a rare parapharyngeal schwannoma of the vagus in the prestyloid compartment mimicking a tonsillar mass. We present our technique of subcapsular excision of vagal nerve schwannoma with complete preservation of nerve function.

\section{Acknowledgements}

We acknowledge the support of the department of Pathology and Anaesthesiology, INHS Asvini without whom this would not have been possible.

\section{Declarations}

Funding: None

Conflict of interest: None declared

Ethical approval: Not required

\section{References}

1. Lahoti BK, Kaushal M, Garge S, et al. Extra vestibular schwannoma: a two year experience. Indian J Otolaryngol Head Neck Surg. 2011;63(4):305309.

2. Gibber MJ, Zevallos JP, Urken ML. Enucleation of vagal nerve schwannoma using intraoperative nerve monitoring. Laryngoscope. 2012;122(4):790-792.

3. Sreevatsa MR, Srinivasarao RV. Three Cases of Vagal Nerve Schwannoma and Review of Literature. Indian J Otolaryngol Head Neck Surg. 2011;63(4):310-312.

4. Kang GC, Soo KC, Lim DT. Extracranial non-vestibular head and neck schwannomas: A ten-year experience. Ann Acad Med Singapore. 2007;36(4):233-238.

5. Liu H, Yu S, Li GK, et al. Extracranial head and neck schwannomas: a study of the nerve of origin. Eur Arch Otorhinolaryngol. 2011;268(9):13431347.

6. Chiofalo MG, Longo F, Marone U, et al. Cervical Vagal Schwannoma: A case Report. Acta Otorhinolaryngol Ital. 2009;29(1):33-35.

7. Behuria S, Rout TK, Pattanayak S. Diagnosis and Management of Schwannomas Originating from the Cervical Vagus Nerve. Ann $R$ Coll Surg Engl. 2015;97(2):92-97.

8. Inderdeep S, Sunil G, Vikas G, et al. Parapharyngeal space schwannomas: our experience and review of literature. International Journal of Otolaryngology and Head and Neck Surgery. 2017;3(2):2454-5929. 